\title{
DR-15
}

\section{LACTONES FORMATION DURING MONOSACCHARIDE'S CARAMELIZATION IN ETHANOLIC-AQUEOUS SOLUTIONS}

\author{
I. S. Cherepanov, O. O. Botalova \\ Udmurt State University. Universitetskaya St, 1, Izhevsk, 426034, Russia. \\ E-mail: cherchem@mail.ru
}

\begin{abstract}
Caramelized carbohydrate's products contain ester functions, which are play a significant role in foodstuff properties, but their formation processes are not considered in detail [1]. In present work sugar lactone's fragments in monosaccharide's thermodestruction products structure were identified using FTIR spectroscopy, several characteristic bands were choosing for structural analysis. The bands at 1164 and $1255 \mathrm{~cm}^{-1}$ are symmetric and asymmetric stretching vibrations of the $-\mathrm{C}(=\mathrm{O})-\mathrm{O}-$ C-group respectively. Complex signal with maxima near $1720 \mathrm{~cm}^{-1}$, assigned to $\mathrm{C}=\mathrm{O}$ stretching vibrations, was resolved using derivative procedures (Figure 1).
\end{abstract}
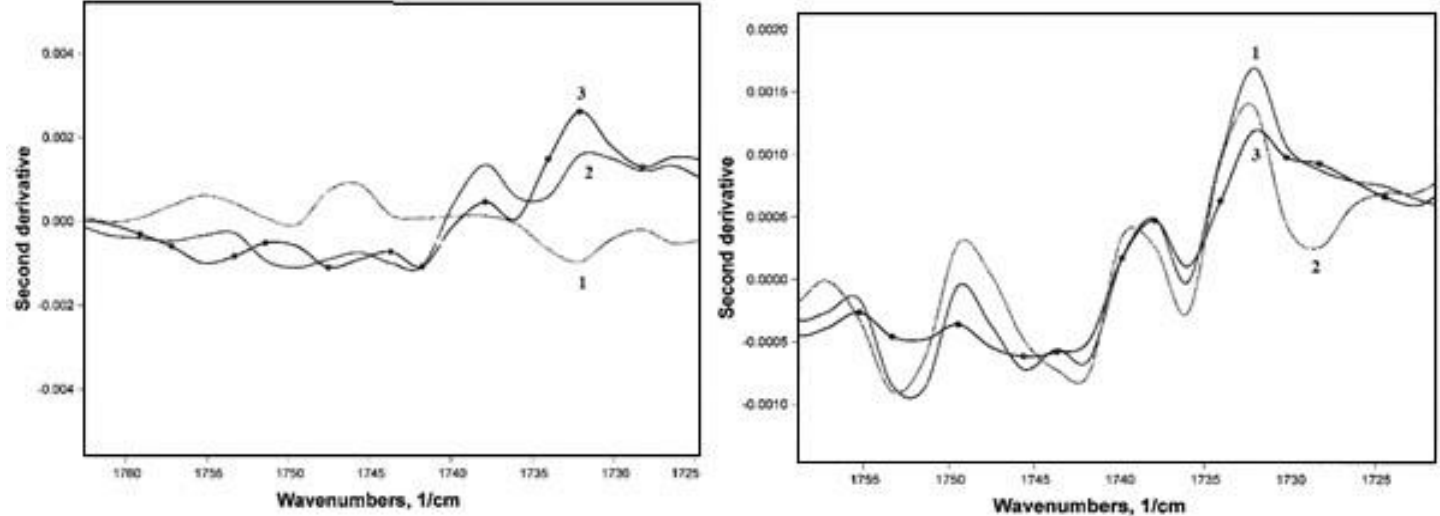

Figure 1. Second derivatives FTIR spectra bands of monosaccharide's caramelized products, synthesized for 1 hour (left) and 1.5 hours (right): 1. - Glc; 2. - Man; 3. - Gal

At 1 hour thermostatting of reaction systems the $1732 \mathrm{~cm}^{-1}$ modes, corresponding to $v_{\mathrm{C}=\mathrm{O}}$ in sixmember saturated $\delta$-lactone ring, were recorded for galactose and mannose systems, as soon as at 1.5 hours thermostatting several bands were observed for all systems, illustrating subsequent functionalization. Positive peak at $1750 \mathrm{~cm}^{-1}$ appears in the spectra of caramelized mannose only, that is due to monosaccharide's lactones conformation type [2]. For glucose and galactose systems half-chair conformer $\left({ }^{4} \mathrm{H}_{3}\right)$ is suggests as predominant form:

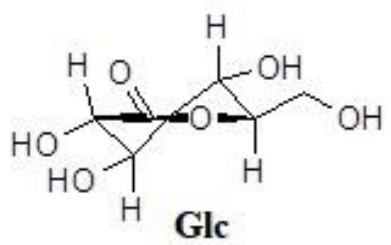

${ }^{4} \mathrm{H}_{3}$

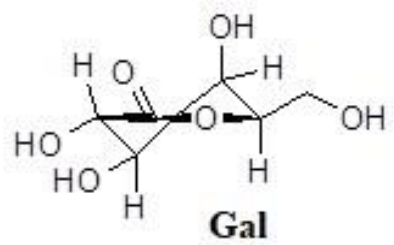

${ }^{4} \mathrm{H}_{3}$

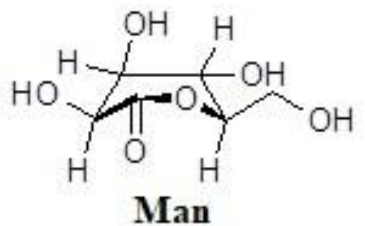

$\mathrm{B}_{2,5}$

and for mannose system a boat conformation $\left(\mathrm{B}_{2,5}\right)$ was proved as more favorable. Equatorial substituent at $\mathrm{C}_{2}$ and lactone function in ${ }^{4} \mathrm{H}_{3}$ are in unfavorable steric interaction [2], leading to further structural transformation [1] and corresponding FTIR bands shift to low frequencies.

\section{References}

1. Maga J. Lactones in foods / J. Maga, I. Katz // Crit. Rev. Food Sci. Nutr. - 1976. - Vol. 8. - P. 1- 56.

2. Bierenstiel M. $\delta$-Galactonolactone: synthesis, isolation, and comparative structure and stability analysis of an elusive sugar derivative / M. Bierenstiel, M. Schlaf // Eur. J. Org. Chem. - 2004. - Iss. 7. - P. 1474-1481. 